\title{
O AVANÇO COMUNITÁRIO DO ENSINO E DA PESQUISA PARA A UNIVERSIDADE DO AMANHÁ
}

\author{
ADVANCING COMMUNITY TEACHING AND RESEARCH FOR THE \\ UNIVERSITY OF TOMORROW
}

\author{
Joedson de Souza Delgado ${ }^{\mathrm{I}}$ \\ Gabrielle Jacobi Kölling ${ }^{\mathrm{II}}$
}

${ }^{\text {I}}$ Universidade de Brasília, Brasília, DF, Brasil. Doutorando em Direito.

${ }^{\text {II }}$ Complexo Educacional Renato Saraiva, Recife, PE, Brasil. Doutora em Direito Público.

DOI: http://dx.doi.org/10.20912/rdc.v16i40.639

Recebido em: 14.10.2021

Aceito em: 12.1.2021
Resumo: Este ensaio se propóe analisar a obra de Darcy Ribeiro, Universidade para quê?, ao idealizar uma mudança social que perpassa pela educaçáo e pela pesquisa em todos os níveis e tipos. O objeto central é de examinar os paradigmas de pesquisa e seus métodos de ensino diante do apelo dos governos e do mercado orientativo para a otimizaçáo dos lucros em detrimento das necessidades sociais. A partir do método dedutivo, da metodologia teórica e da revisão bibliográfica, o texto convida a refletir sobre o futuro das instituiçôes de ensino superior, visto que a imaginação e a ousadia do indivíduo inspiram o acontecimento da vida e disto surgem as soluçóes. A imaginaçáo liberada e a ousadia já tomam e tomaráo cada vez mais a forma de igualdade de oportunidades.

Palavras-chave: Mudança social. Estrutura educacional. Igualdade de oportunidades.

Abstract: This essay aims to analyze the work of Darcy Ribeiro, What University for?, by idealizing a social change that permeates education and research at all levels and types. The main objective is to examine the research paradigms and their teaching methods in view of the appeal of governments and the guiding market for the optimization of profits at the expense of social needs. Based on the deductive method, theoretical and bibliographical methodology, the text invites us to reflect on the future of higher education institutions, as the imagination and daring of the individual inspire the event of life and from this arise the solutions. Unleashed imagination and boldness are already taking and will increasingly take the form of equal opportunity.

Keywords: Social change. Educational structure. Equal opportunity. 


\section{Introdução}

esde a origem das universidades na Idade Média, as instituiçóes de ensino superior
permaneceram, por muito tempo, como um local de ensino. Nesta época até o século XIX lecionavam principalmente direito, medicina e teologia. A pesquisa, portanto, não tinha lugar na Universidade, em vez disso, pertencia as academias reais ou nacionais - equipadas com aparelhos, instrumentos, laboratórios e anfiteatros para a apresentação dos discursos.

A separação entre ensino e pesquisa não seria acidental. Baseia-se, com ou sem razão, no postulado de que o ensino é incompatível com a atividade de pesquisa. Necessitou da contribuição de Wilhelm von Humboldt, diplomata alemão e ministro da Educação, para afirmar que a combinação de ensino e pesquisa melhoraria a qualidade dessas atividades.

Consequentemente, Humbolt reformou a Universidade de Berlim (HumboldtUniversität zu Berlin) em 1810, criando o que agora veio a ser chamado de universidade de pesquisa, composta pelos primeiros professores e pesquisadores. As universidades britânicas e norte-americanas foram fortemente influenciadas por essa reforma alemá.

No Brasil, Darcy Ribeiro, um dos criadores e o primeiro Reitor da Universidade de Brasília, insere um projeto educacional ligada à organização do espaço cívico ao manter relaçóes cada vez mais complexas com a esfera política democrática e a educação pública. As questóes educacionais de ensino e pesquisa - embora a educação obviamente retenha uma dimensão política - ocorre em um espaço e tempo menos ambíguo do que no passado.

O próprio campo da política é cada vez mais difícil de caracterizar por velhas linhas de força. Os lugares de decisão parecem múltiplos e às vezes incertos. A vazante de grandes ideologias leva a duvidar de seu valor explicativo e o desejo de abordagens mais pragmáticas manifestado.

Este ensaio leva a questionar o seguinte problema de pesquisa: as instituiçóes de ensino superior devem adaptar-se aos paradigmas de pesquisa e seus métodos de ensino à luz das demandas dos atores políticos e econômicos das sociedades em que operam?

Assim, o objetivo geral deste ensaio consiste em analisar a educação superior diante da redefinição dos seus fundamentos a partir de uma perspectiva utilitária que permitiu ao aluno definir uma identidade pessoal/moral e desenvolver um pensamento acrítico. De modo geral, as crescentes demandas por accountability e adaptação às mudanças regulatórias formuladas pelos governos e pelo mercado contribuem ou dificultam o desenvolvimento das instituiçóes de ensino superior como espaços de reflexão e conhecimento.

A metodologia utilizada é a pesquisa teórica, de método de argumentação dedutivo cujas revisóes bibliográficas pesquisadas no Google Acadêmico e nos repositórios da SSRN e da Biblioteca Digital Brasileira de Teses e Dissertaçôes (BDTD). A revisão abrangeu materiais precipuamente os eletrônicos, a qual ajudará este ensaísta a desenvolver a compreensão e a descobrir insights/significados relevantes para o problema de pesquisa

Estrutura-se em tópicos sendo o primeiro esta introdução. O segundo tópico aborda o objetivo do ensino superior nas sociedades ocidentais. $\mathrm{O}$ terceiro tópico analisa a expansão da educação superior e as desigualdades sociais com destaque a sua tendência contemporânea. $O$ quarto tópico investiga as implicaçôes políticas da educação superior diante do aumento do nível 
de escolaridade, o que o ajuda, tornar o conhecimento obsoleto. Por fim, apresenta-se uma breve conclusão sobre as instituiçôes de ensino superior que não podem se submeter a demandas de mercado sem se comprometer.

\section{Objetivo do ensino superior nas sociedades ocidentais}

A educação ao orientar e emancipar permite o desenvolvimento intelectual individual e o progresso social. Neste aspecto, o ensino superior serve a um propósito público que vai além de preocupações individualistas ao impor mudanças a fim de refletir a natureza de uma sociedade que seus membros desejam.

Darcy Ribeiro idealizou uma universidade com uma dupla vocação: participar no desenvolvimento da cidadania e na construção de um novo Brasil ${ }^{1}$. Dessa forma, a tarefa do ensino superior não é simplesmente compreender a universidade ou mesmo defendê-la, mas mudá-la.

A finalidade da educação e seu significado nas sociedades ocidentais contemporâneas permitem ampliar o espaço para a emancipação do indivíduo. Pelo tradicional sistema de educação, os alunos não têm a oportunidade de improvisação. Concebe-se, hoje, que a educação deve integrar a inculcação e a emancipação com o propósito de desenvolver intelectualmente o indivíduo e trazer o progresso social.

Nem todos os indivíduos e sociedades concordam com os propósitos e papéis do ensino superior no mundo moderno. Nessa direção, a universidade é um local onde o ensino e a investigação científica podem ser acomodados de forma organizada para a promoção de vários tipos de conhecimentos, aplicados e não aplicados. É um local onde dinheiro e valores morais competem e colaboram simultaneamente, onde o desenvolvimento das aptidóes e competências do mercado de trabalho coexistem com a identificação e valorização das aptidôes e talentos das pessoas, bem como a procura de emprego, moralidade e cidadania.

A era pós-Segunda Guerra Mundial caracterizou-se pela popularização do ensino superior. Antes, o ensino superior era para quem pertencia às classes sociais mais altas ${ }^{2}$. Esse modelo tornou-se o cerne das políticas educacionais na Europa e, em geral, no mundo ocidental impulsionadas pelo advento das tecnologias de informação e comunicação (TIC).

As TIC têm o poder de complementar, enriquecer e transformar positivamente a educação e, assim, aumentar os laços comerciais e não comerciais entre os países e as instituiçôes de ensino superior, transformando ainda mais o seu papel, tornando-o universal ${ }^{3}$. As instituiçóes de ensino superior são agora caracterizadas pela competição econômica em um ambiente de mercado global estrito, onde os governos não são mais os principais atores.

1 RIBEIRO, Darcy. Universidade para quê? Brasília. Editora Universidade de Brasília, 1986.

2 SANTOS, Boaventura de Sousa. Estado e sociedade na semiperiferia do sistema mundial: o caso português. Análise Social, vol. XXI (87-88-89). Instituto Ciências Sociais da Universidade de Lisboa, 1985. Disponível: https://www.jstor.org/stable/41010723 Acessado em: 14 out. 2021.

3 SANTOS, Adriana dos. Tecnologias de informação e comunicação: limites e possibilidades no Ensino Superior. Revista Brasileira de Ensino Superior, Passo Fundo, v. 1, n. 1, p. 36-46, ago. 2015, p. 39-40. Disponível em: https://doi.org/10.18256/2447-3944/rebes.v1n1p36-46 Acesso em: 16 out. 2021. 
Além disso, o ensino superior é agora uma indústria que opera em um mercado global. A competição para atrair talentos de todo o mundo cresce à medida que um número de países oferece cargos adicionais de graduação e pós-graduação para estrangeiros, geralmente a um custo mais alto em comparação com os nacionais ${ }^{4}$.

$\mathrm{O}$ advento de novas tecnologias mudou o modelo tradicional de ensino superior, onde a presença física não é mais um requisito necessário ${ }^{5}$. Estudar enquanto trabalha é muito mais fácil e, portanto, os alunos mais velhos agora têm a oportunidade de estudar para uma graduação ou pós-graduação.

Todos esses desenvolvimentos aumentaram o potencial de lucro, no entanto, também requer uma grande quantidade de dinheiro a ser investida em novas tecnologias e todos os tipos de infraestruturas e recursos. As instituições de ensino superior operam em um ambiente fluido e imprevisível e, portanto, abordagens baseadas na adaptabilidade e flexibilidade são absolutamente cruciais.

Visóes modernas ligadas a economia do ensino superior colocam a sua função educacional numa sociedade digital baseada no conhecimento. Para Bacich, Neto e Trevisani, os mercados de trabalho exigem habilidades como competência tecnológica e resolução de problemas complexos por meio do pensamento crítico e multitarefa, o que aumenta a competição e, por sua vez, acelera o ritmo da jornada de trabalho ${ }^{6}$.

É importante destacar que as tendências de transferência de conhecimento e habilidades pelas universidades, em termos epistemológicos e ontológicos, foram substituídas por um modelo de eficiência e um modelo mercantil ${ }^{7}$. Em todo o caso, o capital humano sob a ótica do investimento não pode ser visto como a ferramenta mais adequada para explicar os benefícios que um indivíduo e a sociedade podem ganhar com a educação.

O capital humano fornecido pelas instituiçóes de ensino superior tem um papel social a cumprir. Quando o objetivo da educaçáo superior for orientado com exclusividade para o mercado de trabalho, o ensino e a pesquisa tornam-se inadequados para responder às necessidades sociais de uma democracia cívica que requer alunos ativos e pensadores críticos. Embora a pesquisa desempenhe um papel crítico em qualquer instituição de nível superior na maioria das instituiçôes não tem cumprido sua função mais básica ${ }^{8}$.

4 HAZELKORN, Ellen. Os rankings e a batalha por excelência de classe mundial: estratégias institucionais e escolhas de políticas. Revista Ensino Superior Unicamp, p. 43-64, 2010. Disponível em: https://bit. ly/31ZjdTL Acesso em: 20 out. 2021.

5 LINHARES, Gabrielle Almeida Silva. Ambientes virtuais de aprendizagem: ferramentas pedagógicas no cenário do ensino superior. 2012. 60f. - TCC (Monografia) - Universidade Federal do Ceará, Faculdade de Educação, Centro de Treinamento e Desenvolvimento, Curso de Especialização em Docência do Ensino Superior, Fortaleza (CE), 2012, p. 27-29. Disponível em: http://repositorio.ufc.br/handle/riufc/41579 Acesso em: 16 out. 2021.

6 BACICH, Adolfo; NETO, Tanzi; TREVISANI; Fernando de Mello. Ensino Híbrido: Personalização e Tecnologia na Educação. Porto Alegre: Penso, 2015. Disponível em: http://repositorio.ufc.br/handle/ riufc/41579 Acesso em: 16 out. 2021.

7 THOMSON, Iain. Heidegger on Ontological Education, or: How We Become What We Are. Inquiry: An Interdisciplinary Journal of Philosophy, issue 3, page 244, volume 44, 2001. Disponível: https://doi. org/10.1080/002017401316922408 Acessado em: 14 out. 2021.

8 ORGANISATION FOR ECONOMIC CO-OPERATION AND DEVELOPMENT. Higher Education Management and Policy. Journal of the Programme on Institutional Management in Higher Education, volume 17, no. 2, p. 10, 2005. Disponível em: https://www.oecd.org/education/imhe/42348396.pdf Acesso em: 19 out. 2021. 
Nos termos da OCDE, a educação superior contribui para o desenvolvimento social e econômico por meio do ensino (a formação de capital humano); por meio da pesquisa e desenvolvimento de conhecimento (a construçâo de bases de conhecimento); por meio de interaçôes com usuários do conhecimento (a disseminação e uso do conhecimento); e por meio armazenamento da transmissão intergeracional de conhecimento (a manutenção do conhecimento $)^{9}$. A educação superior é um grande contribuinte para a competitividade econômica em uma economia global cada vez mais orientada para o conhecimento.

Tais mudanças decorrentes da economia alteram a relação que os países de renda média têm com a educação superior. Por este prisma, a interrelação entre educação, economia e sociedade é essencial para compreender as implicações das mudanças nas condiçóes sociais e econômicas atuais, bem como as prováveis consequências das recentes reformas políticas.

Por tudo isso, a desigualdade na educação pode ser compreendida medindo o que é "boa educação" e "educação ruim" e como isso é distribuído pela população como um todo. Isso pode então ser debatido por meio de conceitos como "igualdade de resultados" e "igualdade de oportunidades". Para Bourdieu, o ideal de igualdades de oportunidades substitui paulatinamente a função institucional de educação por uma função de integração profissional ${ }^{10}$.

Pensando nisso, a cidadania vai além de ter um emprego e uma profissão delineados por critérios tácitos estabelecidos pela classe dominante objetivando identificar pessoas de um determinado contexto social. Os alunos devem ser capazes de expressar seus pensamentos e participar em suas comunidades locais e nacionais ao invés voltar o conteúdo e o currículo acadêmico colocar o mundo empresarial como os atores principais.

\section{Expansáo do ensino superior e o aprofundamento das desigualdades sociais}

As taxas de matrícula no ensino superior têm aumentado continuamente "por força da continuidade da demanda e da inércia do sistema" ${ }^{11}$. No Brasil, as políticas direcionadas para a ampliação do acesso ao ensino superior contemplam a heterogeneidade da população para a qual as políticas são direcionadas a vários grupos socioeconômicos, demográficos, étnicos, entre outros.

A heterogeneidade destaca-se no setor de ensino superior privado. É marcada por uma forte competição entre instituiçóes de ensino superior privadas, e entre estas e o setor público. Pode ser observado no setor privado de ensino superior o processo de reproduçáo social - até mesmo reforço das desigualdades. A expansão do ensino superior pelo setor privado também reforça as desigualdades e as divisôes entre e dentro das classes sociais ${ }^{12}$.

9 ORGANISATION FOR ECONOMIC CO-OPERATION AND DEVELOPMENT. Tertiary Education for the Knowledge Society: OECD Thematic Review. Paris: Organisation for Economic Co-operation and Development, 2008. Disponível em: https://www.oecd.org/education/skills-beyond-school/41266690.pdf Acesso em: 19 out. 2021.

10 BOURDIEU, Pierre et Jean-Claude. Passeron, Les Héritiers, Paris, Éditions de Minuit: 1964. Disponível em: https://bityli.com/knVRBW Acesso em: 18 out. 2021.

11 PORTO, Claudio; RÉGNIER, Karla. O Ensino Superior no Mundo e no Brasil - Condicionantes, Tendências e Cenários para o Horizonte 2003-2025: Uma Abordagem Exploratória. Dezembro, 2003, p. 58. Disponível: https://cutt.ly/NRakvQX Acessado em: 14 out. 2021.

12 GERAD, Etienne. L'expansion de l'enseignement supérieur privé et le creusement des inégalités sociales. Analyses à partir de l'Argentine, de l'Inde, du Mexique, du Pérou,de la République Démocratique du 
Os propósitos institucionais nem sempre coincidem com as expectativas dos alunos em relaçáo aos estudos. Em boa parte dos casos existe um descompasso entre expectativa e realidade acadêmica dado que os alunos possuem uma compreensão mais pragmática e instrumental em relação ao objetivo do ensino superior, visando principalmente a empregos mais bem remunerados e o sucesso na carreira no nível individual.

Este novo modelo educacional redefine o papel tradicional da transmissão de conhecimentos teóricos e práticos nos diferentes campos de estudo na medida em que enfatiza a sua dimensão de aplicabilidade para a ação e a possibilidade de transferir para várias situaçóes e contextos. Além disso, também incorpora as habilidades, atitudes e outras aptidōes individuais que proporcionam uma prática profissional competente ${ }^{13}$.

Silva, Maranhão e Gontijo descrevem que as desigualdades na educação são apenas uma transformação das desigualdades sociais e uma forma de reprodução do status quo social ${ }^{14}$. O modelo instrumental contemporâneo de preparar os alunos para enfrentar as mudanças ocorridas nos locais de trabalho falha em reduzir as desigualdades de classe, uma vez que as relaçôes de classe social são reproduzidas por meio da escolaridade.

O modo neoliberal de mercantilizar os sistemas educacionais com vistas a aumentar a qualidade da educação não condiz com variados estudos que mostram que a expansão do ensino superior ocorre em paralelo com o aumento da desigualdade de renda e o agravamento das diferenças raciais, de gênero e classe ${ }^{15,16,17}$. Desfigurou-se as noçóes básicas que caracterizam o propósito da educaçáo, como pensamento crítico, justiça e equidade.

A iniciativa privada na educação superior é um modelo de racionalidade: movida pela busca do lucro em mercados competitivos, busca constantemente aumentar sua produtividade para atender a demanda com o menor custo. Ressalte-se, também, que o modelo privado de ensino superior difere do público quanto a eliminação dos poderes colegiais; o abandono da estabilidade prevista no estatuto do serviço público; o estabelecimento de objetivos de resultados mensuráveis; a restrição a liberdade de cátedra; as motivaçóes do professor por incentivos

Congo, du Sénégal, du Vietnam. Papiers de recherche. Octobre, 2020, p. 2. Disponível em: https://bit. ly/2XpCy71 Acesso em: 19 out. 2021.

13 VAN DER HEIJDE, Cláudia M.; VAN DER HEIJDEN, Beatrice I. J. M. A competence-based and multidimensional operationalization and measurement of employability". Human Resource Management, 45, pp. 449-476, 2006. Disponível: https://doi.org/10.1002/hrm.20119 Acessado em: 14 out. 2021.

14 SILVA, Ívina Pereira da; MARANHÃO, Carolina Machado Saraiva de Albuquerque; GONTIJO, Felipe Marques Carabetti. Como a Escola mantém o Status Quo? Alguns dos Principais Ensinamentos de Bourdieu e Passeron sobre a Educação Crítica. II Encontro de Ensino e Pesquisa em Administração e Contabilidade. Associação Nacional de Pós-Graduação e Pesquisa em Administração - ANPAD, Curitiba/PR: 2009, p. 5-6. Disponível em: http://www.anpad.org.br/admin/pdf/EnEPQ228.pdf Acesso em: 18 out. 2021.

15 BARROS, César Mangolin de. Higher education in Brazilian society: analysis of the historical and sociological determinants of the expansion of higher education in Brazil (decades of 1960/70). 2008. p. 81-87. Dissertação (Mestrado em Educação) - Universidade Metodista de São Paulo, São Bernardo do Campo, 2008. Disponível em: http://tede.metodista.br/jspui/handle/tede/1094 Acesso em: 18 out. 2021.

16 CARVALHO, Cristina Helena Almeida de. Reforma universitária e os mecanismos de incentivo à expansão do ensino superior privado no brasil (1964- 1984). Dissertaçáo (Mestrado em Ciências Econômicas) Universidade Estadual de Campinas, 2002, p. 105-110. Disponível em: https://bityli.com/2ivSAt Acesso em: 18 out. 2021.

17 LOPES, Roberto Paulo Machado. Universidade, externalidades e desenvolvimento regional: As dimensóes socioeconômicas da expansão do ensino superior em Vitória da Conquista. Tese (Doutorado em Geografia, Planificación Territotrial y Géstion Ambiental) - Universitat de Barcelona, 2012, p. 219. Disponível em: https://bityli.com/Owhqdb Acesso em: 18 out. 2021. 
materiais; a introdução de ferramentas de gestáo para empresas privadas; e as auditorias da qualidade dos processos realizadas por empresas de avaliação (International Organization for Standardization - ISO).

É necessária uma reforma estrutural nos sistemas educacionais em todo o mundo, onde a relação entre as várias comunidades sociais e o Estado seja baseada na justiça social e não no poder. Com efeito, uma desigualdade qualificada como social é obra da comunidade em que é observada. Isso exclui desigualdades náo produzidas pela sociedade, sejam suprassociais (encontrando sua origem/na natureza) ou intrassociais (resultantes de decisóes, comportamentos, atitudes dos próprios indivíduos).

Eckert assinala que as desigualdades sociais não devem se reduzir a fatores de igualdade de oportunidades ${ }^{18}$. A igualdade correlaciona-se com as liberdades reais ao desempenhar um papel de difusão em todas as práticas sociais, diversificando assim o campo das desigualdades em termos de habitação, consumo, condiçôes de vida, acesso à saúde etc. A esse respeito quanto mais desigual uma sociedade é na distribuição de renda, mais sua população sofre com problemas sociais e de saúde.

As mudanças fundamentais na educação estão relacionadas à influência que vários fatores socioeconômicos e culturais têm na formulação de políticas ${ }^{19}$. Os interesses corporativos na formulação de políticas educacionais podem transformar o ensino superior em um sistema de castas que reproduz e intensifica as desigualdades sociais.

O neoliberalismo é ideologia perigosa para o momento histórico da educação superior. Giroux aborda os efeitos corrosivos da cultura empresarial nas instituiçóes de ensino superior e as recentes tentativas de professores e alunos de resistir à corporatizaçáo do ensino superior ${ }^{20}$.

A par disso, Giroux relata que o discurso cívico deu lugar à linguagem da comercialização, privatização e desregulamentação e que, dentro da linguagem e das imagens da cultura corporativa, a cidadania é retratada como um assunto totalmente privatizado que forma indivíduos com interesses próprios ${ }^{21}$. Afirma que a cultura empresarial funciona em grande parte para ignorar ou cancelar as injustiças sociais na ordem social dominante, substituindo as práticas democráticas da sociedade civil por meio de uma ênfase no funcionamento das relaçóes de mercado.

A expansão da participação no ensino superior cria um mercado de credenciais podendo causar em desvalorização do trabalho. Isso se relaciona a hiper valorização do diploma em que o mercado de trabalho cria uma falsa impressão de que um diploma superior é um pré-requisito para um emprego e, portanto, induz o cidadão a buscá-lo apenas para conseguir trabalho ${ }^{22}$.

18 ECKERT, Henry. Bihr A. et Pfefferkorn R. (2008), Le système des inégalités: La Découverte, coll. «Repères». Formation emploi, 104, 83-87, 2008. Disponível em: https://bit.ly/31QWjhi Acesso em: 18 out. 2021.

19 FERNANDES, Florestan. A ciência aplicada e a educação como fatores de mudança cultural provocada. Revista Brasileira de Estudo Pedagógicos, Brasília, v. 86, n. 212, p. 144-159, jan./abr. 2005. Disponível em: https://doi.org/10.24109/2176-6681.rbep.86i212.853 Acesso em: 18 out. 2021.

20 GIROUX, Henry. Neoliberalism, Corporate Culture, and the Promise of Higher Education: The University as a Democratic Public Sphere. Harvard Educational Review (2002) 72 (4): 451-460. Disponível em: https:// doi.org/10.17763/haer.72.4.0515nr62324n71p1 Acesso em: 19 out. 2021.

21 GIROUX, Henry. Neoliberalism, Corporate Culture, and the Promise of Higher Education: The University as a Democratic Public Sphere. Harvard Educational Review (2002) 72 (4): 451-460. Disponível em: https:// doi.org/10.17763/haer.72.4.0515nr62324n71p1 Acesso em: 19 out. 2021.

22 PAULO, Francivone da Costa; ALMEIDA, Ilda Neta Silva de; CARVALHO, Valter Domingos Rezende. Os 
O papel da educação formal e a utilidade da aquisição de habilidades dentro das universidades determinam o estrato social. Esta, por sua vez, pode criar um mercado de credenciais altamente competitivo e, mesmo havendo a expansão do ensino superior, os cidadáos dos estratos sociais mais baixos não têm oportunidades iguais de obter um diploma, o que pode levá-los a uma categoria ocupacional de menor prestígio.

Deve-se valorizar os conhecimentos tácitos - que não podem ser adquiridas por meio da aprendizagem formal - principalmente obtidas por meio da experiência de trabalho e de vida, bem como da aprendizagem informal. Tais experiências são competências relacionadas à maneira como uma situação complexa pode ser melhor abordada ou assemelhar-se a traços pessoais usados para lidar com situaçóes imprevistas.

\section{Implicaçóes políticas com o aumento do nível de escolaridade}

O aumento do nível de escolaridade que leva a um determinado grau acadêmico é um procedimento dinâmico, mas com um fim pré-definido. Isso torna o conhecimento adquirido obsoleto. Nesse sentido, as instituiçóes de ensino superior devem reconhecer os benefícios que o nível de escolaridade superior traz para as sociedades como um todo pela promoçáo simultânea da produtividade, inovação e democratização, incluindo a mitigação das desigualdades sociais.

Não é convincente a narrativa política de oportunidades iguais em termos de taxas de empregabilidade devido a aquisição do ensino superior. A agenda de empregabilidade, constantemente promovida nas instituiçóes de ensino superior não pode ser considerada uma justificativa sustentável em um ambiente global diverso. Ademais disso, existe o risco de que o ensino superior torne uma ferramenta nas mãos das forças baseadas no mercado com diferentes prioridades e interesses para o setor.

Vê-se que o ethos mercantilista é um conceito-chave no ensino superior na contemporaneidade. A taxa de emprego do discente da pós-graduação é frequentemente usada para avaliar a qualidade de ensino universitário, embora empregabilidade e emprego sejam dois conceitos diferentes ${ }^{23}$. A empregabilidade do governo prioriza o desenvolvimento e a acreditação de conhecimentos e habilidades vocacionais, os empregadores enfatizam as habilidades sociais e as atitudes ${ }^{24}$.

O papel das Instituiçóes de Ensino Superior vai além de garantir que os alunos tenham conhecimento em uma disciplina acadêmica. Isso posto, o aumento do interesse pela empregabilidade como uma resposta pragmática é atribuído a uma série de fatores, incluindo a preocupação de que os graduados têm menos probabilidade de garantir empregos no

obstáculos encontrados pelos recém-formados de pedagogia na busca do seu primeiro emprego: a formação inicial não é o suficiente. Revista Multidebates, v.4, n.1, Palmas -TO, abril de 2020. Disponível em: https:// bit.ly/3INPXiF Acesso em: 18 out. 2021.

23 DINIZ, Rosa Virgínia; GOERGEN, Pedro L. Educação Superior no Brasil: panorama da contemporaneidade. Avaliação: Revista de Avaliação da Educação Superior, Campinas; Sorocaba, SP, v. 24, n. 03, p. 583, nov. 2019. Disponível em: http://dx.doi.org/10.1590/S1414-40772019000300002 Acesso em: 18 out. 2021.

24 CHENG, Ming et al. Employability in higher education: a review of key stakeholders' perspectives. Higher Education Evaluation and Development, vol. ahead-of-print, no. ahead-of-print. Disponível em: https://doi. org/10.1108/HEED-03-2021-0025 Acesso em: 20 out. 2021. 
setorpúblicodevido à massificação do ensino superior ${ }^{25}$. $\mathrm{O}$ enxugamento e a reestruturação das organizaçôes privadas devido às políticas neoliberais colocam ainda mais pressão sobre a disponibilidade de trabalho da graduação e da pós-graduação ${ }^{26}$.

Sabendo disso, a economia de mercado atinge o ensino superior quando organizaçóes internacionais e empresas interferem na formulação de políticas educacionais. Estas políticas deterioram o caráter humanístico da educação afetando o pensamento intelectual e crítico do indivíduo ao mesmo tempo que perpetua as desigualdades sociais.

A Organização para a Cooperação e Desenvolvimento Econômico - OCDE analisou as políticas para o ensino superior dos seus países membros com base no orçamento público da educação. A publicação Education at a Glance - EAG 2020 da OCDE constatou que a Educação Superior brasileira consta que a metade dos recursos do governo federal com ensino superior beneficiam os mais ricos da população ${ }^{27}$. Diante dessa perspectiva, Soares coloca o debate sob um quadro político mais amplo, justapondo as ideias neoliberais e a competitividade do mercado global às tendências formuladas pela OCDE e do Banco Mundial28.

$\mathrm{Na}$ prática, o ensino superior não pode ser apenas conceituado pela abordagem do capital humano e interpretaçóes quantitativas, visto que o conhecimento de competências se torna obsoleto. As implicaçóes culturais, psicológicas e sociais da educação superior desempenham um papel significativo no processo de tomada de decisão do indivíduo.

A teoria do capital humano conecta o dogma historicamente à importância da educação para o desenvolvimento econômico e social já enfatizado por Adam Smith ${ }^{29}$. Com o modelo teórico neoclássico, fenômenos reais, como salários diferenciados, só podiam ser explicados de maneira insuficiente. Nesse ponto, a teoria do capital humano resolveu esse problema ao incluir o fator educação ao colocar essa variável em relação direta com a renda do trabalho e, assim, explicar as diferenças de renda do estoque diferenciado de capital humano.

Para Lefebvre, a problemática separação entre o trabalho humano e os saberes necessários permite introduzir o conhecimento como fator adicional de produção ${ }^{30}$. O entendimento de que capital humano é intangível permite equacionar com os meios de produção o capital real. Em linha com os investimentos em capital físico, os investimentos em capital humano também aumentam a produtividade.

25 PASICHNYK, Inesa Volodymyrivna. O percurso dos diplomados da Universidade do Porto (2013/2014). Dissertaçáo (Mestrado em Economia) - Universidade do Porto, 2018, p. 59-61. Disponível em: https:// repositorio-aberto.up.pt/bitstream/10216/117230/2/301524.pdf Acesso em: 18 out. 2021.

26 SILVA, Maria Emília Pereira da. A metamorfose do trabalho docente no ensino superior: entre o público e o mercantil. 2009. 184 f. Tese (Doutorado em Educaçáo) - Universidade do Estado do Rio de Janeiro, Rio de Janeiro, 2009, p. 23. Disponível em: http://www.bdtd.uerj.br/handle/1/14803 Acesso em: 18 out. 2021.

27 ORGANISATION FOR ECONOMIC CO-OPERATION AND DEVELOPMENT. Education at a Glance 2021: OECD Indicators. Paris, France: 2021, p. 268. Disponível em: https://bit.ly/3vpPOoN Acesso em: 18 out. 2021.

28 SOARES, Fabiana Pegoraro. A influência do Banco Mundial e da OCDE na educação básica no Brasil e no ensino de geografia. Geografia Ensino \& Pesquisa, 24, e15, 2020. Disponível: https://doi. org/10.5902/2236499441843 Acessado em: 14 out. 2021.

29 TEIXEIRA, Pedro. A Different Canon? Education and the Economic System in the work of Rodrigues de Freitas (1840-1896). e-Journal of Portuguese History, vol. 13, number 1, pp. 89-105, June 2015, p. 99-101. Disponível: https://scielo.pt/pdf/ejph/v13n1/v13n1a04.pdf Acessado em: 19 out. 2021.

30 LEFEBVRE, Henri. A reproduçáo das relaçóes de produção. Coleção Difusão Cultural, v. 4, $1^{a}$ edição Goiânia: Ediçôes REDELP, 2020. 
O investimento em capital humano aumenta a produtividade do trabalho e produz um retorno na forma de salários mais altos aproximadamente o equivalente à receita de juros do investimento em capital real. Este tratamento igual do investimento em capital humano e investimento em capital físico significa que a educação superior também pode ser medida de acordo com os critérios de despesas e receitas.

A obsolescência de competências é uma parte integrante da teoria do capital humano, uma vez que os investimentos neste capital apenas indicam os investimentos brutos em competências e conhecimento. Para Figueiredo Neto, o investimento líquido em capital humano só pode ser determinado quando a deterioraçáo do capital humano ao longo do tempo é levada em consideração ${ }^{31}$.

A obsolescência de competências - se relaciona com o processo de degradação de competências individuais ou a diminuição do valor de certas competências - deve, portanto, ser considerada ao analisar a relação entre os investimentos em capital humano e os resultados do mercado de trabalho. Chama atenção da teoria do capital humano quando se tornou aparente que a obsolescência das competências do trabalhador pode ser considerada a principal razáo pela qual os trabalhadores individuais precisam de atualização contínua de suas habilidades ao longo da carreira para permanecerem suficientemente produtivos.

A decisão de cursar o ensino superior não é influenciada apenas pelo seu valor agregado no mercado de trabalho, uma vez que um indivíduo está exposto a diferentes experiências e influências, as decisóes estratégicas podem facilmente ser alteradas. Diante disso, as percepçóes e preferências mudam com o amadurecimento e é por isso que algumas pessoas abandonam a universidade, outros optam por mudanças radicais na carreira e outros retornam à educação após terem trabalhado no mercado de trabalho por longos anos e em diferentes tipos de empregos.

\section{Consideraçóes finais}

O advento de novas tecnologias dita o aprimoramento da expertise ocupacional e a criação de uma economia competitiva e produtiva impulsionada para o talento e criatividade. Por sua vez, a inovação assume um papel central na condução dos mercados o que exige trabalhadores nas áreas de ciência e tecnologia ainda mais qualificados.

Desde a expansão do ensino superior no pós-Segunda Guerra Mundial tem-se observado que está e tem estado em constante luta por sua definição e propósito. De um lado, o seu processo contínuo de mercantilização, tornando o ensino superior menos acessível as pessoas de camadas econômicas desfavorecidas, do outro lado, é um instrumento para amenizar as desigualdades sociais e de renda. Enquanto o ensino superior perpetuar a criação de comunidades de acadêmicos produtivos continuará a influenciar e ser influenciado pelas expectativas da sociedade.

O propósito do ensino superior e seu papel nas sociedades modernas permanece em veemente debate filosófico, com fortes implicaçóes políticas. No quadro da economia convencional, a noção intrínseca de ensino superior é tratada como um componente dos eixos políticos ligado à dinâmica do mercado de trabalho quanto a competitividade e empregabilidade.

31 FIGUEIREDO NETO, Leonardo Francisco. Retornos privados aos investimentos em capital humano: evidências da PNAD-1995. Dissertação (Mestrado em Ciências) - Universidade de São Paulo, 1997, p. 8387. Disponível em: https://bit.ly/3vo7SzC Acesso em: 18 out. 2021. 
A obra de Darcy Ribeiro, Universidade para quê?, lança luz sobre o debate da vocação das instituiçôes de ensino superior diante das configuraçôes institucionais contemporâneas relacionadas ao poder, dominação e raciocínio econômico. Ao apresentar as percepçóes das pessoas sobre o propósito do ensino superior, o texto é uma base para futuras pesquisas teóricas e empíricas na compreensão das tendências contemporâneas no ensino superior entrelaçadas com as evoluçôes na esfera socioeconômica mais ampla.

O desafio da universidade é lidar com a complexidade da sociedade e com a aceleração das mudanças nas áreas demográficas, econômicas, científicas, tecnológicas, sociais e culturais que deve promover a adaptação do aluno em mundo em rápida mutação. Diante das demandas pragmáticas que pesam sobre a educação e a cultura, as atividades reflexivas perdem relevância em que tem menos a ver com questionar ou compreender este mundo do que com aprender a se encaixar e a funcionar nele.

\section{Referências}

BACICH, Adolfo; NETO, Tanzi; TREVISANI; Fernando de Mello. Ensino Híbrido: Personalização e Tecnologia na Educação. Porto Alegre: Penso, 2015. Disponível em: http:// repositorio.ufc.br/handle/riufc/41579 Acesso em: 16 out. 2021.

BARROS, César Mangolin de. Higher education in Brazilian society: analysis of the historical and sociological determinants of the expansion of higher education in Brazil (decades of 1960/70). 2008. 125 f. Dissertaçáo (Mestrado em Educaçáo) - Universidade Metodista de São Paulo, São Bernardo do Campo, 2008. Disponível em: http://tede.metodista.br/jspui/ handle/tede/1094 Acesso em: 18 out. 2021.

BOURDIEU, Pierre et Jean-Claude. Passeron, Les Héritiers, Paris, Éditions de Minuit: 1964. Disponível em: https://bityli.com/knVRBW Acesso em: 18 out. 2021.

CARVALHO, Cristina Helena Almeida de. Reforma universitária e os mecanismos de incentivo à expansão do ensino superior privado no brasil (1964- 1984). Dissertaçáo (Mestrado em Ciências Econômicas) - Universidade Estadual de Campinas, 2002. Disponível em: https://bityli.com/2ivSAt Acesso em: 18 out. 2021.

CHENG, Ming et al. Employability in higher education: a review of key stakeholders' perspectives. Higher Education Evaluation and Development, vol. ahead-of-print, no. ahead-of-print. Disponível em: https://doi.org/10.1108/HEED-03-2021-0025 Acesso em: 20 out. 2021.

DINIZ, Rosa Virgínia; GOERGEN, Pedro L. Educação Superior no Brasil: panorama da contemporaneidade. Avaliação: Revista de Avaliação da Educação Superior, Campinas; Sorocaba, SP, v. 24, n. 03, p. 573-593, nov. 2019. Disponível em: http://dx.doi.org/10.1590/ S1414-40772019000300002 Acesso em: 18 out. 2021.

ECKERT, Henry. Bihr A. et Pfefferkorn R. (2008), Le système des inégalités: La Découverte, coll. «Repères». Formation emploi, 104, 83-87, 2008. Disponível em: https://bit.ly/3lQWjhi Acesso em: 18 out. 2021. 
FIGUEIREDO NETO, Leonardo Francisco. Retornos privados aos investimentos em capital humano: evidências da PNAD-1995. Dissertaçáo (Mestrado em Ciências) - Universidade de São Paulo, 1997. Disponível em: https://bit.ly/3vo7SzC Acesso em: 18 out. 2021.

FERNANDES, Florestan. A ciência aplicada e a educação como fatores de mudança cultural provocada. Revista Brasileira de Estudo Pedagógicos, Brasília, v. 86, n. 212, p. 125-161, jan./ abr. 2005. Disponível em: https://doi.org/10.24109/2176-6681.rbep.86i212.853 Acesso em: 18 out. 2021.

GERAD, Etienne. L'expansion de l'enseignement supérieur privé et le creusement des inégalités sociales. Analyses à partir de l'Argentine,de l'Inde, du Mexique, du Pérou,de la République Démocratique du Congo, du Sénégal, du Vietnam. Papiers de recherche. Octobre, 2020. Disponível em: https://bit.ly/2XpCy71 Acesso em: 19 out. 2021.

GIROUX, Henry. Neoliberalism, Corporate Culture, and the Promise of Higher Education: The University as a Democratic Public Sphere. Harvard Educational Review (2002) 72 (4): 425-464. Disponível em: https://doi.org/10.17763/haer.72.4.0515nr62324n71p1 Acesso em: 19 out. 2021.

HAZELKORN, Ellen. Os rankings e a batalha por excelência de classe mundial: estratégias institucionais e escolhas de políticas. Revista Ensino Superior Unicamp, p. 43-64, 2010. Disponível em: https://bit.ly/31ZjdTL Acesso em: 20 out. 2021.

LEFEBVRE, Henri. A reproduçáo das relaçóes de produçáo. Coleção Difusão Cultural, v. 4, $1^{a}$ edição - Goiânia: Ediçóes REDELP, 2020.

LINHARES, Gabrielle Almeida Silva. Ambientes virtuais de aprendizagem: ferramentas pedagógicas no cenário do ensino superior. 2012. 60f. - TCC (Monografia) - Universidade Federal do Ceará, Faculdade de Educação, Centro de Treinamento e Desenvolvimento, Curso de Especialização em Docência do Ensino Superior, Fortaleza (CE), 2012. Disponível em: http://repositorio.ufc.br/handle/riufc/41579 Acesso em: 16 out. 2021.

LOPES, Roberto Paulo Machado. Universidade, externalidades e desenvolvimento regional: As dimensões socioeconômicas da expansão do ensino superior em Vitória da Conquista. Tese (Doutorado em Geografia, Planificación Territotrial y Géstion Ambiental) - Universitat de Barcelona, 2012. Disponível em: https://bityli.com/Owhqdb Acesso em: 18 out. 2021.

ORGANISATION FOR ECONOMIC CO-OPERATION AND DEVELOPMENT. Higher Education Management and Policy. Journal of the Programme on Institutional Management in Higher Education, volume 17, no. 2, 2005. Disponível em: https://www. oecd.org/education/imhe/42348396.pdf Acesso em: 19 out. 2021.

ORGANISATION FOR ECONOMIC CO-OPERATION AND DEVELOPMENT. Tertiary Education for the Knowledge Society: OECD Thematic Review. Paris: Organisation for Economic Co-operation and Development, 2008. Disponível em: https:// www.oecd.org/education/skills-beyond-school/41266690.pdf Acesso em: 19 out. 2021. 
ORGANISATION FOR ECONOMIC CO-OPERATION AND DEVELOPMENT.

Education at a Glance 2021: OECD Indicators. Paris, France: 2021. Disponível em: https:// bit.ly/3vpPOoN Acesso em: 18 out. 2021.

PASICHNYK, Inesa Volodymyrivna. O percurso dos diplomados da Universidade do Porto (2013/2014). Dissertaçáo (Mestrado em Economia) - Universidade do Porto, 2018. Disponível em: https://repositorio-aberto.up.pt/bitstream/10216/117230/2/301524.pdf Acesso em: 18 out. 2021.

PAULO, Francivone da Costa; ALMEIDA, Ilda Neta Silva de; CARVALHO, Valter Domingos Rezende. Os obstáculos encontrados pelos recém-formados de pedagogia na busca do seu primeiro emprego: a formação inicial não é o suficiente. Revista Multidebates, v.4, n.1, Palmas -TO, abril de 2020. Disponível em: https://bit.ly/3INPXiF Acesso em: 18 out. 2021.

PORTO, Claudio; RÉGNIER, Karla. O Ensino Superior no Mundo e no Brasil Condicionantes, Tendências e Cenários para o Horizonte 2003-2025: Uma Abordagem Exploratória. Dezembro, 2003. Disponível: https://cutt.ly/NRakvQX Acessado em: 14 out. 2021.

RIBEIRO, Darcy. Universidade para quê? Brasília. Editora Universidade de Brasília, 1986.

SANTOS, Adriana dos. Tecnologias de informação e comunicação: limites e possibilidades no Ensino Superior. Revista Brasileira de Ensino Superior, Passo Fundo, v. 1, n. 1, p. 36-46, ago. 2015. Disponível em: https://doi.org/10.18256/2447-3944/rebes.v1n1p36-46 Acesso em: 16 out. 2021.

SANTOS, Boaventura de Sousa. Estado e sociedade na semiperiferia do sistema mundial: o caso português. Análise Social, vol. XXI (87-88-89). Instituto Ciências Sociais da Universidade de Lisboa, 1985. Disponível: https://www.jstor.org/stable/41010723 Acessado em: 14 out. 2021.

SILVA, Maria Emília Pereira da. A metamorfose do trabalho docente no ensino superior: entre o público e o mercantil. 2009. 184 f. Tese (Doutorado em Educação) - Universidade do Estado do Rio de Janeiro, Rio de Janeiro, 2009. Disponível em: http://www.bdtd.uerj.br/ handle/1/14803 Acesso em: 18 out. 2021.

SILVA, Ívina Pereira da; MARANHÃO, Carolina Machado Saraiva de Albuquerque; GONTIJO, Felipe Marques Carabetti. Como a Escola mantém o Status Quo? Alguns dos Principais Ensinamentos de Bourdieu e Passeron sobre a Educação Crítica. II Encontro de Ensino e Pesquisa em Administração e Contabilidade. Associação Nacional de PósGraduação e Pesquisa em Administração - ANPAD, Curitiba/PR: 2009. Disponível em: http://www.anpad.org.br/admin/pdf/EnEPQ228.pdf Acesso em: 18 out. 2021.

SOARES, Fabiana Pegoraro. A influência do Banco Mundial e da OCDE na educação básica no Brasil e no ensino de geografia. Geografia Ensino \& Pesquisa, 24, e15, 2020. Disponível: https://doi.org/10.5902/2236499441843 Acessado em: 14 out. 2021.

TEIXEIRA, Pedro. A Different Canon? Education and the Economic System in the work of Rodrigues de Freitas (1840-1896). e-Journal of Portuguese History, vol. 13, number 1, pp. 
89-105, June 2015. Disponível: https://scielo.pt/pdf/ejph/v13n1/v13n1a04.pdf Acessado em: 19 out. 2021.

THOMSON, Iain. Heidegger on Ontological Education, or: How We Become What We Are. Inquiry: An Interdisciplinary Journal of Philosophy, issue 3, pages 243-268, volume 44, 2001. Disponível: https://doi.org/10.1080/002017401316922408 Acessado em: 14 out. 2021.

VAN DER HEIJDE, Cláudia M.; VAN DER HEIJDEN, Beatrice I. J. M. A competencebased and multidimensional operationalization and measurement of employability". Human Resource Management, 45, pp. 449-476, 2006. Disponível: https://doi.org/10.1002/ hrm.20119 Acessado em: 14 out. 2021. 